\title{
Meeting family planning needs of factory workers in Port Said: Lessons from pilot testing an intervention in eight garment factories
}

Maryam Essam

Population Council

Nahla G. Abdel-Tawab

Population Council

Elizabeth Tobey

Population Council

Aparna Jain

Population Council

\section{Recommended Citation}

Essam, Maryam, Nahla G. Abdel-Tawab, Elizabeth Tobey, and Aparna Jain. 2021. "Meeting family planning needs of factory workers in Port Said: Lessons from pilot testing an intervention in eight garment factories," Policy brief. Washington DC: Population Council, The Evidence Project. 


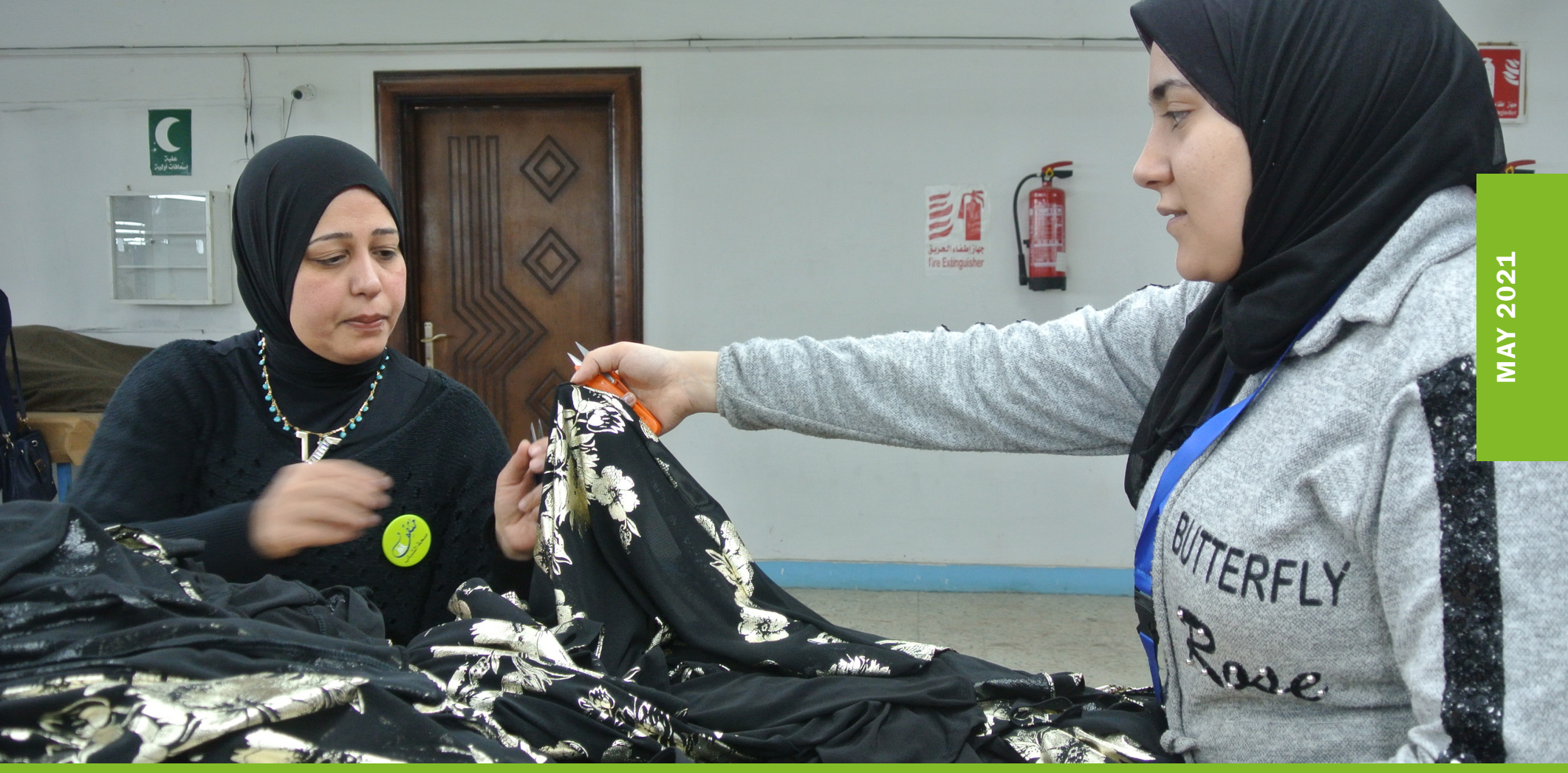

POLICY BRIEF

\section{Meeting family planning needs of factory workers in Port Said: Lessons from pilot testing an intervention in eight garment factories}

\section{HIGHLIGHTS}

- Worker health programs offer a unique venue for raising young people's awareness of family planning/reproductive health (FP) $\mathrm{RH}$ ) issues and available services.

- Factory workers can play an important role in sharing $\mathrm{FP} / \mathrm{RH}$ information with their coworkers.

- Factory nurses' roles can be expanded to include $\mathrm{FP} / \mathrm{RH}$ counseling for workers as well as referrals for $\mathrm{FP} / \mathrm{RH}$ services.
- Factories with large numbers of female workers could consider on-site women's health clinics to address workers' FP/RH needs.

- Factory health committees for worker health program management may help enhance their sustainability. 


\section{BACKGROUND}

To generate demand for private sector FP/RH services among Egyptian garment factory workers in Port Said's Free Investment Zone, the Population Council/Evidence Project, with the U. S. Agency for International Development (USAID)/Egypt funding and in collaboration with Egypt's Port Fouad Childhood and Motherhood Association, led implementation science that aimed to increase worker demand for private sector FP/RH services as well as their quality and availability for young people throughout the governorate (Figure 1).

\section{FIGURE 1: MAIN GOALS OF THE RESEARCH PROJECT}

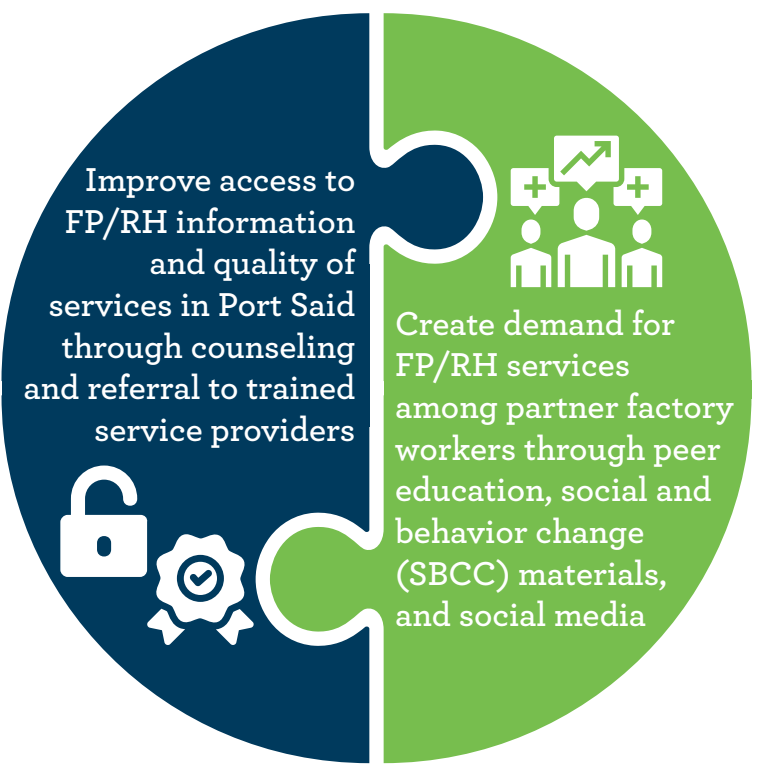

Although Egypt's fertility rates have declined since the late 1980s, in 2014 a reversal occurred: The country's total fertility rate increased from 3.0 births per woman in 2008 to 3.5 in 2014 (Ministry of Health and Population, El Zanaty and Associates and ICF 2015). Even though young people under the age of 30 comprise $60 \%$ of Egypt's population (CAPMAS 2018), FP awareness campaigns rarely focus on youth because it is assumed young couples desire children immediately following marriage. Not only does this leave young people-married or unmarried-without the knowledge and tools to prevent unintended pregnancy, but it also leaves them susceptible to inaccurate FP/RH information (Roudi-Fahimi and El Feki 2011).

Worker health programs that offer health education to factory workers at their places of work could be an important venue for reaching young Egyptians with FP messages as well as increasing their demand for and use of FP/RH services. Traditionally, worker health programs have focused on occupational health and safety compliance, and only recently have they begun expanding their scope to improve workers' overall health and well-being (Evidence Project 2016). Evidence from a number of countries shows that female factory workers' awareness of $\mathrm{RH}$ and general health topics, along with their use of clinic services, increase as a result of awareness-raising activities in factories (Yeager 2011, Hossain 2017).

The Population Council/Evidence Project FP/RH intervention among factory workers in Port Said was implemented for a period of three years. This policy brief provides lessons from its implementation and offers recommendations for designing FP/RH worker health programs. These lessons and recommendations are based on insights from factory worker program beneficiaries, their peer educators, factory managers, and project staff.

\section{SETTING}

Port Said is an urban governorate with a population of about 750,000 (CAPMAS 2018) that has a relatively high contraceptive prevalence rate (CPR): $59 \%$ of married women ages 15 to 49 use an FP method, and 57\% use a modern method (Ministry of Health and Population, El Zanaty and Associates and ICF 2015). Port Said's Free Investment Zone's 27 factories employ nearly 38,000 people, of whom nearly $60 \%$ are women and $65 \%$ are 18 to 35 years of age. Every factory production site has an infirmary staffed by a nurse that provides basic first aid for work-related ailments and injuries. More than half of Port Said's factory workers commute by factory bus to the Free Investment Zone from neighboring governorates where FP information and services are not easily accessible, and CPRs are lower than in Port Said.

\section{INTERVENTION}

This project's intervention began in 2017, focusing on male and female workers in five garment factories in the Free Investment Zone, then expanded to three additional factories in 2019, to include a total of eight factories.

At the beginning of the intervention, 30 to 40 male and female workers were selected at each participating factory, in consultation with factory management, to serve as peer educators (Box 1). Peer educators were not paid for their work with the project but were trained for three days on $\mathrm{FP} / \mathrm{RH}$, communications skills, and use of social media to convey health messages to their peers. 


\section{BOX 1: KEY PROJECT ACTIVITIES}

300 male and female peer educators were trained in communicating health messages.

35 factory nurses were trained in FP counseling.

\section{7 pharmacists and 64 private} physicians were trained in FP service provision.
Peer educators also introduced their coworkers to Ma3looma: Family Planningi (Arabic for "information"), a social media Facebook page that features animated videos and other information on $\mathrm{FP} / \mathrm{RH}$ topics, including myths and facts about FP.

Peer educators were trained to refer co-workers to factory nurses, who were trained by the project in FP/RH counseling. Workers interested in receiving a FP method were then referred by factory nurses to a network of private physicians and pharmacists also trained by the project in $\mathrm{FP} / \mathrm{RH}$ service provision.

After three years of implementation, in June 2020, a total of 20 in-depth telephone interviews were conducted with 10 factory workers, six peer educators, and four factory managers, in addition to implementing nongovernmental organization (NGO) staff. These interviews were conducted by trained male and female data collectors. Results of a quantitative survey that measured effects of the intervention on workers' FP knowledge, attitudes, and practices are described elsewhere (Abdel-Tawab et al. 2019).

\section{LESSONS FROM IMPLEMENTATION}

\section{PEER EDUCATORS COULD SERVE AS A CREDIBLE SOURCE OF INFORMATION FOR THEIR PEERS}

Several peer educators reported initial difficulty in establishing themselves as credible sources of information, especially on topics not widely discussed-such as FP/ $\mathrm{RH}$. At first, some factory workers thought discussions with peer educators would waste their time at work, but this perception gradually changed as they began to hear the information peer educators were sharing and considered its benefits. One female factory worker (25 years old) said, "The peer educator gave us messages and we always turned to her whenever we needed any information or advice. for me, it was much easier to ask [the peer educator] than to ask my mother because I consider her to be closer...."

Eventually, peer educators became recognized as reliable sources of information on various health topics, sought out rather than avoided. As described by a female peer educator (22 years old), "There is a huge need for this

Ma3looma: Family Planning is a Facebook page that offers information and answers questions about FP (https://www.facebook.com/ma3loma.tanzim/) 
type of $[F P / R H]$ information because they have several unanswered questions. There were times when I could not keep up with the number of questions." Several male peer educators indicated that it was difficult to persuade their male coworkers, due to the sensitivity of the topic and general perception that FP is a "woman's business," but eventually male factory workers, especially those about to be married, developed an interest in these conversations and started approaching peer educators with questions.

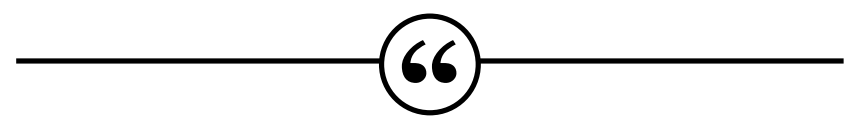

... Of course, I used to receive some silly jokes and unnecessary comments from my colleagues, but they began to understand as time passed. Afterwards, some people came to me when they had questions or have an issue with a certain FP method.... With time, people began to understand that peer educators are not silly, but s/he is a helpful person who delivers useful pieces of information that we can benefit from.

-Male peer educator, 46 years old

\section{WORKING AS A PEER EDUCATOR HAD POSITIVE INFLUENCES ON PEER EDUCATORS, INCLUDING THEIR RELATIONSHIPS WITH THEIR CO- WORKERS, FAMILIES, AND FRIENDS}

Peer educators reported a number of benefits from their involvement in the project, including improved relationships with peers, friends, and family. FP is often considered taboo in Egypt, with most information passed from older generations, rooted in culture and tradition, and often riddled with misconceptions, and consequently peer educators consider their role critically important. Peer educators themselves benefited from the information they were tasked with disseminating. One female peer educator (35 years old) said, "We benefited from the information in so many ways. It corrected several misconceptions that we previously had...you know, what our parents had taught us as well as the old customs and traditions."

Peer educators also reported that their families and friends came to them for accurate and credible answers to their FP/RH questions. Many female peer educators were surprised by their ability to discuss such sensitive topics with their mothers, many of whom were apparently exposed to this type of information for the first time in their lives, although they had been married for many years. One female peer educator (22 years old) said, "Some coworkers would tell me that they talked about these topics with their mothers. We were all able to discuss these sensitive topics with them for the first time. This was the first time they heard this information, although some of them were married for years."

Several peer educators strengthened relations with co-workers as a result of their conversations about health matters. Peer educators reported increased self-confidence as well as improved communication and teamwork skills because of their participation in the intervention. An added sense of social responsibility was cultivated among peer educators through their participation, with many coming to see their role from a new perspective: as a moral imperative.

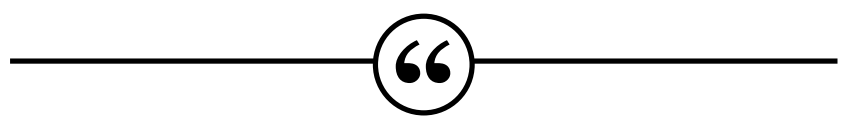

I have built several friendships with people. I participated in the project because I deal with many of my coworkers and because of my interest in the topic. I also benefited from the information and booklet they gave us. That's why I wanted to disseminate the information to my colleagues, as I was able to gain new information that I did not previously know.

-Female peer educator, 34 years old

\section{THE NATURE OF FACTORY WORK MAY CONSTRAIN PEER EDUCATORS' ABILITIES TO CONVEY MESSAGES IN PERSON}

Several peer educators reported limited time for interactions with their co-workers due to work responsibilities, including being recalled to work, to not disrupt production lines, as soon as they started speaking to co-workers. These work conflicts made conveying messages to the initial target of 40 to 50 co-workers every month difficult, so the target was adjusted to 20 to 25 factory workers for each peer educator. Peer educators with some degree of mobility, such as line supervisors, security guards, or human resources personnel, were able to reach more 
co-workers. One male peer educator (48 years old) said, "You see, our time is really limited during our working day. The working hours at the Port Said Free Investment Zone are from 8 AM till 3 PM, and we only get a 30-minute break. So, there isn't enough time to meet and have those discussions, because this can disrupt the workers."

\section{SOCIAL MEDIA CAN BE A POWERFUL TOOL FOR COMMUNICATING HEALTH MESSAGES TO FACTORY WORKERS, BUT NOT WITHOUT CHALLENGES}

As a result of challenges with direct, in-person communication, peer educators formed WhatsApp groups to communicate health messages to their co-workers. Several WhatsApp groups were established between peer educators and 25 to 30 factory workers of the same sex. Peer educators noted the benefits of these WhatsApp groups, especially when in-person communication was not feasible. According to one male peer educator (40 years old), "With the WhatsApp groups, I send those pieces of information and they can easily access and read them at home when they are not under work pressure."

Many workers also preferred WhatsApp to Facebook because they do not have Facebook accounts and could not access the Ma3looma: Family Planning Facebook page, while others thought WhatsApp was easier to access and use. While WhatsApp is an efficient tool that ensures delivery of health messages to fairly large numbers of workers at the same time, there were some difficulties in WhatsApp messaging implementation. Many female workers were hesitant to share their phone num-

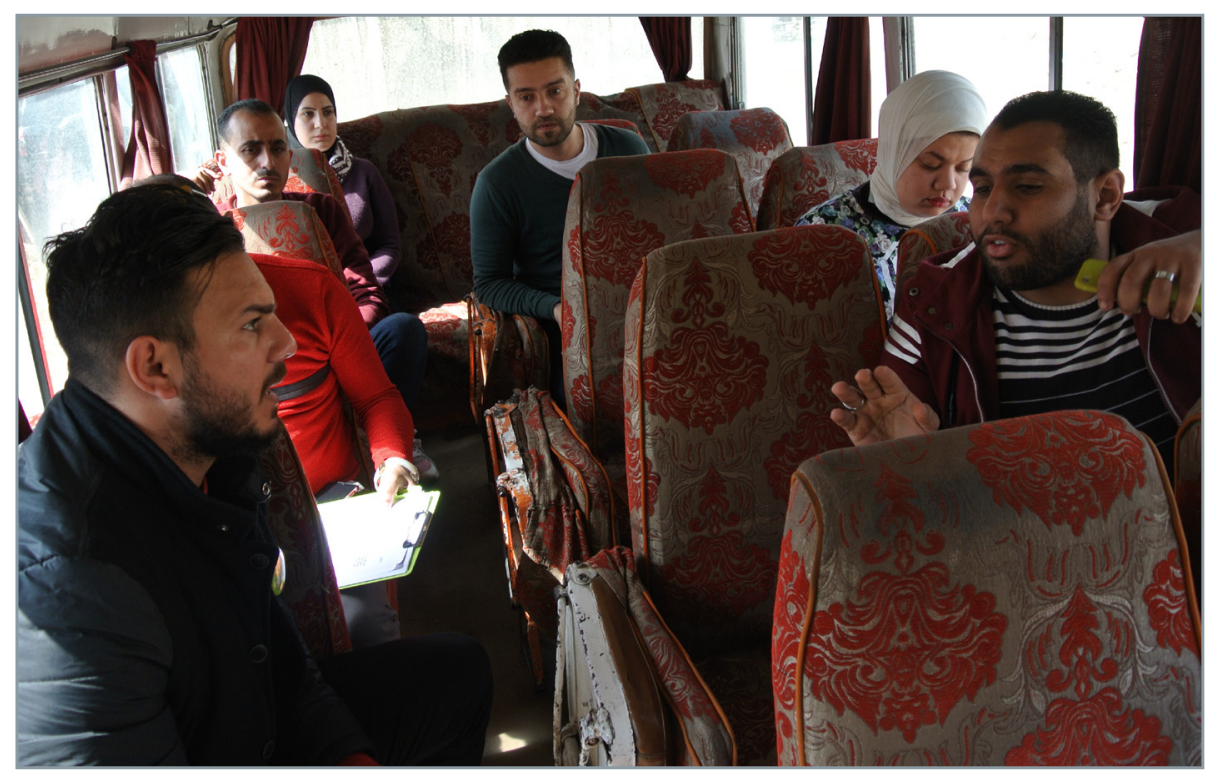

bers with peer educators, even if they personally knew them. Moreover, the WhatsApp groups were set up to only allow peer educators to send messages, and not vice versa, and this one-way communication restricted exchanges of information among peer educators and co-workers. In some cases, workers exited the group.

Social media platforms such as the Ma3looma: Family Planning Facebook page were well received, especially among younger workers, as highlighted during qualitative interviews. One female factory worker ( 25 years old) said, "Ma3looma Facebook page has a lot of information. It is useful because even our neighbors and friends can access it to obtain information." Factory workers mentioned that animated videos and graphically designed posts were preferable to Facebook posts with text information only because they are more visually appealing. Several peer educators and factory workers reported recommending the Facebook page to their friends and relatives.

\section{MULTIPLE MEANS OF COMMUNICATING HEALTH MESSAGES TO FACTORY WORKERS CAN ENSURE A VARIETY OF AUDIENCES ARE REACHED}

Older workers are less likely to have smart phones or utilize social media, and prefer direct, personal communications and printed SBCC materials, which still provide important tools at peer educators' disposal that can be shared with any co-worker, at almost any time, to read at their convenience. Basic internet access can still be a challenge for many factory workers, especially those living in smaller villages. One female peer educator (35 years old) said, "Honestly, not everyone here can access WhatsApp easily. WhatsApp was a great idea, but some of them do not even have their own smart phones that can access Facebook and WhatsApp. Those would need face-to-face communication."

During monthly project review meetings, peer educators posited that the long bus rides to and from work for commuters from other governorates provide an opportunity to discuss health messages with colleagues, and further disseminate information to among individuals and additional communities in those governorates. 


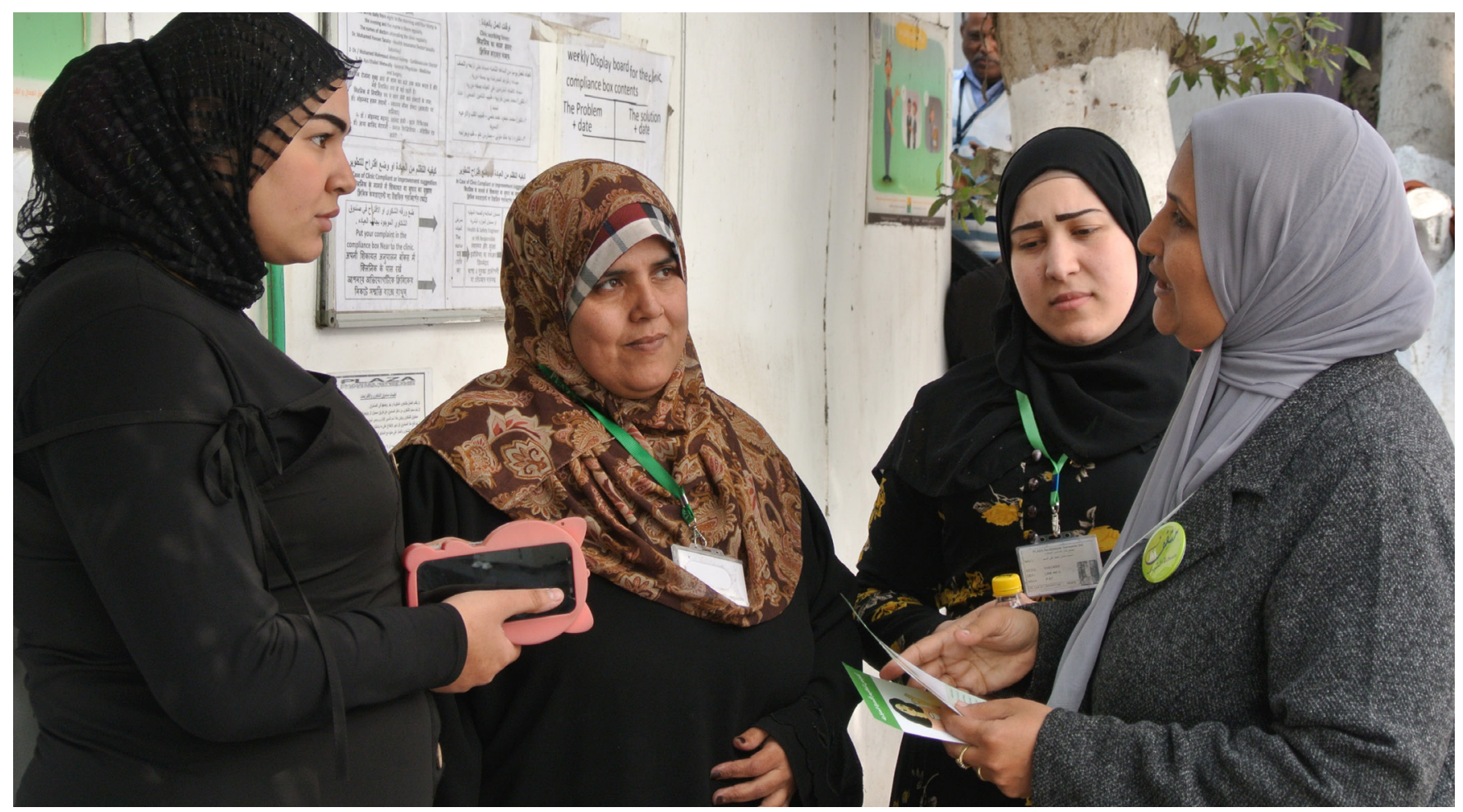

\section{PROGRAM SUSTAINABILITY IN FACTORIES IS A CHALLENGE}

Staff attrition is a routine challenge at garment factories, where employment patterns are also seasonal, which further increases staffing changes. High attrition among trained peer educators and their co-workers reduced the sustainability of awareness-raising activities. Staff changes also made monitoring and evaluation activities particularly challenging, as some workers assigned to intervention and comparison groups likely moved to other factories during the intervention period. One male factory manager mentioned, "There is a high turnover among workers in the apparel industry, but I think having SBCC materials can help the workers carry the information as they move around factories."

\section{FACTORY WORKERS NEED ACCESS TO AFFORDABLE FP SERVICES TO ADDRESS DEMAND ISSUES}

Factory nurses referred workers who needed FP services to a network of private physicians or pharmacists trained by the project. Factory workers who live in Port Said benefitted from this network, although some found private doctors' fees to be high. Some physicians offered discounts to workers referred by factory nurses, but on an ad hoc basis. One female peer educator (35 years old) said, "Workers in the private sector cannot afford to go to private physicians. This is why this project is important."
Factory workers who live in other governorates could not benefit from these referral services or discounted rates due to having to take a factory bus home immediately after work.

With funds from the Etisalat Foundation and support from the Investors' Association, the project started the first Women's Health Clinic at the Free Investment Zone, which is expected to serve more than 20,000 female workers in the Zone by providing subsidized FP services at discounted rates.

\section{6}

We have wanted a clinic here for a long time. The project made that happen. This will make a huge difference because many workers go to the nurse for counseling and when the nurse refers them to private physicians they can't afford to go. When we have a clinic in the Investment Zone with a qualified and trained physician, workers will benefit. This made the workers very happy.

-Female peer educator, 30 years old 
INVESTMENT FROM FACTORY

MANAGEMENT IS ESSENTIAL FOR SUCCESS OF FP/RH WORKER HEALTH PROGRAMS

Factor managers frequently asked project staff, "What gains do we stand to make from those interventions?" Several managers saw the project as beneficial only for workers and expressed concerns about potential production disruptions due to the peer education process. Factory managers also had reservations about FP/RH messaging among their workers. One manager objected to the provision of FP commodities in his infirmary due to fear of legal liability.

The project engaged in direct communication with management and ensured program transparency during implementation to address any concerns quickly and convince management that addressing workers' FP/RH needs can contribute to the collective good at their factories, management and workers included. Several managers were encouraged by their workers' improved morale and its potential for increasing productivity, in addition to gains from workers' overall improved health.

Long term success and commitments to improvement can be achieved by engaging factory management (Evidence Project 2016). A new paradigm that views workplace health as a strategic investment and business priority is vital for workers' health programs and their sustainability.

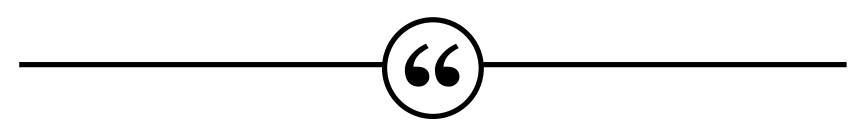

You see, it is really hard to disrupt the production line for half an hour due to the nature of work in the factory, so my role was to explain to the general manager and the middle management the benefits of this project to the workers and its positive impact on production as well. As long as a worker's health is good, he will be able to put in more effort and increase the total quantities produced.

-Female manager, 38 years old

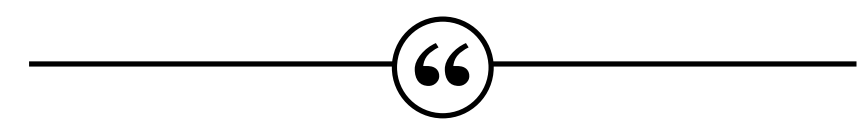

The idea of integrating family planning and general health into the factory was great. It made the workers feel that they were valuable because we, along with the NGO, valued their health and wellbeing. It also made us become trustworthy as the workers and peer educators got back to us whenever they had questions regarding the workers' general health.

-Male manager, 37 years old

\section{RECOMMENDATIONS}

- Integrating FP/RH information and services within worker health programs in factories is a potentially effective approach for addressing Egyptian young people's FP/RH needs, given the country's large factory workforce and relatively young population.

- Factories should consider mechanisms for providing workers with FP/RH services, including on-site factory clinics, or contracting with private provider networks that can provide discounted FP/RH services.

- Social media should be considered as a channel for reaching large numbers of factory workers, especially younger ones, with FP/RH messages.

- To enhance worker health programs' sustainability, business owners need to invest in training opportunities for factory nurses and their peer educators, as well as supporting $\mathrm{FP} / \mathrm{RH}$ service provision on their premises, and the production and distribution of related SBCC materials.

- Factory health committees comprised of various stakeholders could be a valuable component, providing sustainable structures within factories that could manage their worker health programs.

- Research demonstrating a return on investment from $\mathrm{FP} / \mathrm{RH}$ integration within worker health programs could engender advocacy and convince business owners of its importance, both for economics and profitability, in addition to social responsibility. 


\section{REFERENCES}

Abdel-Tawab, Nahla, Norhan Bader, Elizabeth Tobey, and Aparna Jain. 2019. "Two implementation models of workers' health education programs in Egypt: What works? What doesn't work?," Research Brief. Washington, DC: Population Council, The Evidence Project.

Central Agency for Public Mobilization and Statistics. 2017. http://www.capmas.gov.eg/Pages/ ShowPDF.aspx?page_id=/Admin/Pages\%20Files/ 201710914947book.pdf

Evidence Project. 2016. "Strengthening Factory Health Systems under Levi Strauss \& Co.'s Worker Well-being Initiative in Egypt." Washington, DC: Population Council, Evidence Project.

Hossain, Md. Irfan et al. 2017. "Evaluation of the effectiveness of the HERhealth model for improving sexual and reproductive health and rights knowledge and access of female garment factory workers in Bangladesh," Research Report. Washington, DC \& Dhaka, Bangladesh: Population Council, The Evidence Project.

Ministry of Health and Population [Egypt], El-Zanaty and Associates [Egypt], and ICF International. 2015. Egypt Demographic and Health Survey 2014. Cairo, Egypt and Rockville, Maryland, USA: Ministry of Health and Population and ICF International

Roudi-Fahimi, F. and S. El Feki. 2011. "Facts of life: Youth sexuality and reproductive health in the Middle East and North Africa." Washington, DC: Population Reference Bureau.

Roushdy, Rania and Maia Sieverding. 2015. "Panel survey of young people in Egypt 2014: Generating evidence for policy, programs, and research." Cairo: Population Council.
Venkatraman Chandra-Mouli, Catherine Lane, and Sylvia Wong. 2015. "What does not work in adolescent sexual and reproductive health: A review of evidence on interventions commonly accepted as best practices," Global Health: Science and Practice 3(3): 333-340. doi: 10.9745/GHSP-D-15-00126.

World Bank. 2019. https://data.worldbank.org/indicator/SP.POP.GROW?locations $=E G$

Yeager, Rachel. 2011. HERproject: Health Enables Returns. BSR and Levi Strauss Foundation.

\section{ACKNOWLEDGMENTS}

We are grateful to the individuals and organizations who made this brief possible. Special thanks go to the factory managers and Port Fouad Childhood and Motherhood Association for their continued support during implementation of this project. We acknowledge the contributions of our Population Council colleagues Tarek Alam Eldin, Nesrine Fouad, Nada Wahba and Sally Radwan during study implementation. We are thankful for the data collection team for ensuring the quality of data collection. Last, but not least, we wish to thank the study participants for their time and for sharing their experiences during the interviews.

\section{THE EVIDENCE PROJECT}

Population Council 4301 Connecticut Ave, NW, Suite 280

Washington, DC 20008

evidenceproject@popcouncil.org

(C) 2021 The Population Council, Inc

Photo credits:

(C)2021 Heba El Kalaawy,

Population Council Egypt Consultant
The Evidence Project is made possible by the generous support of the American people through the United States Agency for International DeFROM THE AMERICAN PEOPLE
OAA-A-13-00087. The contents of this document are the sole responsibility of the Evidence Project and Population Council and do not necessarily reflect the views of USAID or the United States Government.

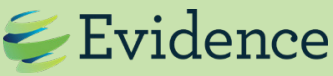

The Evidence Project uses implementation science-the strategic generation, translation, and use of evidence-to strengthen and scale up family planning and reproductive health programs to reduce unintended pregnancies worldwide. The Evidence Project is led by the Population Council.

Suggested Citation: Essam, Maryam, Nahla Abdel-Tawab, Elizabeth Tobey, and Aparna Jain. 2021. "Meeting family planning needs of factory workers in Port Said: Lessons from pilot testing an intervention in eight garment factories," Policy Brief. Washington DC: Population Council, The Evidence Project. 